BULLETIN Bulletin hispanique

HISPANIQUE Université Michel de Montaigne Bordeaux

117-1 | 2015

Les poètes des rhéteurs

\title{
La poesía en el Culto Sevillano de Juan de Robles
}

la evocación del sueño del Humanismo en Sevilla

José Manuel Rico García

\section{OpenEdition}

Journals

Edición electrónica

URL: https://journals.openedition.org/bulletinhispanique/3787

DOI: 10.4000/bulletinhispanique.3787

ISSN: 1775-3821

Editor

Presses universitaires de Bordeaux

Edición impresa

Fecha de publicación: 1 junio 2015

Paginación: 143-158

ISBN: 979-10-300-0174-7

ISSN: 0007-4640

Referencia electrónica

José Manuel Rico García, «La poesía en el Culto Sevillano de Juan de Robles», Bulletin hispanique [En línea], 117-1 | 2015, Publicado el 01 junio 2018, consultado el 12 febrero 2022. URL: http://

journals.openedition.org/bulletinhispanique/3787 ; DOI: https://doi.org/10.4000/bulletinhispanique. 3787 


\title{
La poesía en el Culto Sevillano de Juan de Robles: la evocación del sueño del Humanismo en Sevilla ${ }^{1}$
}

\author{
José Manuel Rico García \\ Universidad de Huelva
}

On tente de mettre au jour les raisons qui motivent le recours fréquent à la poésie dans El culto sevillano (1631) et d'expliquer la position adoptée par Robles dans la controverse de l'époque sur le renouveau du langage poétique.

Mots-clés : Juan de Robles, rhétorique, poésie sévillane du Siècle d'Or.

El presente trabajo examina las razones de la presencia recurrente de la poesía en $E l$ culto sevillano (1631) y trata de dilucidar las motivaciones del planteamiento adoptado por Robles en el contexto de la controversia de su tiempo sobre las novedades de la lengua poética.

Palabras claves: Juan de Robles, retórica, cultismo, poesía sevillana del Siglo de Oro.

This essay analyses the causes of the recurring appearance of poetry in El culto sevillano (1631) and endeavours to explain the reasons of Robles' position within the time controversy about the revival of poetic language.

Keywords: Juan de Robles, Rethorics, cultism, Sevilian Golden Age poetry.

1. Este artículo se ha financiado con el proyecto El canon de la lírica áurea: constitución, transmisión e historiografia (III), FFI2011-27449, Dirección General de Investigación (Ministerio de Economía y Competitividad). 
Tuan de Robles ${ }^{2}$ (1575-1649) ha pasado a la historia de la literatura áurea por ser el autor de El culto sevillano $(1631)^{3}$, un tratado en forma de diálogo que constituye una de las retóricas castellanas más audaces y originales del siglo XVII. Tal originalidad hace del Culto una retórica poco convencional, heterodoxa, si se quiere, para su tiempo y para su género. No es una obra destinada a las aulas universitarias ni a la formación de los predicadores, como la mayor parte de las obras retóricas de su época. Su singularidad está ya presente en el título mismo: El culto sevillano. Título ambiguo, alejado de las fórmulas comunes aplicadas a estos tratados. En él no asoman los términos trillados: arte, instituciones, elocuencia, retórica; El culto sevillano, tal cual. Un sintagma equívoco del que era imposible concluir que daba nombre a una retórica. $\mathrm{Ni}$ siquiera Quevedo, cuya aprobación aparece al frente del manuscrito autógrafo conservado en la Biblioteca Capitular de Sevilla ${ }^{4}$, preparado para su impresión, indica en su censura que la materia sea la retórica, antes pondera los «donaires onestos i decentes que hacen sabrossa su leçión" "; cualidades, desde luego, poco comunes a las artes sobre el bien discurrir. En esas dos palabras de un título tan anómalo para una retórica se contienen, en nuestra opinión, las claves para interpretar la intención, los contenidos y los procedimientos expositivos de la obra. Esas dos palabras, en fin, son las portadoras de su sentido último. De manera que en lo que sigue nos proponemos dar respuesta a esa cuestión: ¿por qué Juan de Robles tituló su tratado El culto sevillano? Responder a ello supone también explicar la intensa presencia de la poesía en el Culto, otro de los rasgos diferenciadores de este tratado en relación con los de su tiempo ${ }^{6}$, que, en general, demostraron una gran indiferencia hacia la creación poética.

Antonio Vilanova fue el primero en apreciar que la novedad del Culto no solo radicaba en el «talento de escritor que ha sobrepuesto a la rutina pedantesca de los tratados de retórica una exposición elegante y amena, sino que estriba en ser la primera retórica crítica de la literatura española» (Vilanova 1951: 668). Esa intención crítica le sobrevino, entre otras razones que expondremos, porque Robles concibió una retórica escrita para instruir a un culto determinado a convertirse en un crítico literario.

Robles advierte que su obra solo se ocupará de «los puntos más principales de la Retórica» (Robles 1992: 200), que para él son los que considera útiles y necesarios para el ejercicio bien fundado de la crítica literaria. Estos puntos

2. Los datos biográficos y bibliográficos esenciales sobre Juan de Robles pueden consultarse en la entrada bio-bibliográfica correspondiente al autor realizada por Alejandro Gómez Camacho en Jauralde (2010: II, 279-282). También el estudio preliminar de la reciente edición de las Tardes del Alcázar incluye un excelente esbozo biográfico; véase Robles (2010: 13-17).

3. Citaremos por la edición de Alejandro Gómez Camacho, Sevilla (Robles, 1992). El culto fue impreso por primera vez por la Sociedad de Bibliófilos andaluces, en Sevilla, 1883.

4. Es el manuscrito 56-4-38 de la Biblioteca Capitular y Colombina de Sevilla, lleva por título Primera parte de El Culto Sevillano. Se trata de un volumen en cuarto, preparado para su impresión, que contiene los preliminares y las aprobaciones.

5. Aprobación del Culto sevillano; Robles (1992: 39).

6. Es uno de los rasgos distintivos que ha subrayado López Bueno (2010) en un trabajo dedicado a la contribución de las retóricas del siglo XVII al canon de la poesía española. 
son, como ha subrayado y descrito Gómez Camacho (Robles 1992: 30), la amplificación en la dispositio y el adorno y acomodo en la elocutio. Y, en efecto, la inventio y la dispositio, salvo lo que concierne a la amplificatio, las despacha de forma trivial y breve. En este sentido, el Culto es un tratado que ilustra de forma inequívoca el designio de la retórica barroca, en palabras de Martí, «un mero empeño por conseguir un buen estilo» (Martí 1972: 264).

En lo que concierne a las fuentes, también ofrece signos de su heterodoxia. Baltasar de Céspedes es el modelo del Culto, que compendia los preceptos de Del arte de la retórica y De los elementos ${ }^{7}$. Así lo declara abiertamente: «Empero quien juntó todo lo perteneciente al Arte, con tal eminencia que no dexa nada que desear, fue el Maestro Baltasar de Céspedes que es este manuscrito que está aquí, el cual podrá llevar V. M. para estudiar por él todo quanto quisiere» (Robles 1992: 72). En efecto, la retórica de Céspedes aportó el contenido doctrinal, pero sus preceptos adquieren una intención y significado nuevos en el contexto en el que se inscriben. En el proceso de formación que se recrea en el diálogo entre el Licenciado Sotomayor, alter ego de Robles, como definió al personaje Gómez Camacho, y el joven don Juan de Guzmán, las fuentes documentales son solo retóricas escritas en castellano, que conoce al dedillo y que pone ante los ojos del discípulo:

De las que yo tengo noticias son estas que V. M. verá aquí. Esta es la más antigua, que escribió un Padre del Orden de san Ierónimo sin expresar su nombre ${ }^{8}$, i en verdad que si no fuera tan rara i dificultosa de hallarse que pudiera escusar de hazer otras en cuanto a Invención y Disposición.

Esta es más pequeña (que parece epítome de la pasada) es de Rodrigo Espinosa de Santayana9.

Esta es la Eloquencia del Maestro Ximénez Patón ${ }^{10}$, que parece querer suplir lo que falta a las otras de la locución. Fue escrita primero en este volumen pequeño, i ahora sale en el libro que digo del Mercurio ${ }^{11}[\ldots]$

No le doi a V.M. estos Combites de Iuan de Guzmán ${ }^{12}$ porque están dispuestos para

7. Así se refiere Robles a la Rhetórica en romance, fechada en 1597 y conservada en los manuscritos BNE, 2327, texto compuesto de 55 fols., y al manuscrito de la Real Biblioteca II/1004, pp. 139-333, que lleva por título De el arte de la retórica.

8. En este punto habla solo de las retóricas escritas en castellano; aquí se refiere a la Rethórica en lengua castellana de fray Miguel de Salinas, que había publicado Brocar en Alcalá en 1541. Las ediciones modernas que pueden consultarse de esta retórica son las de Casas (1980: 39-200); Artaza (1997: 257-260; «La memoria»); y Salinas (1999).

9. Se refiere al Arte de retórica en el cual se contienen tres libros. El primero enseña el arte generalmente. El segundo particularmente, el arte de Historiador. El tercero escribir epistolas y diálogos, Madrid, Casa de Guillermo Drouy, 1578.

10. Se trata de la Elocuencia española en arte, Toledo, Thomás de Guzmán, 1604. Hay edición moderna con un amplio estudio, Jiménez Patón (1993).

11. Libro de la elocuencia española en arte, reeditado y enmendado en el Mercurius Trimegistus, sive triplici eloquentiae sacra, española, romana, Baeza, Pedro de la Cuesta Gallo, 1621.

12. Hace aquí referencia a la Primera parte de la Rhetórica... dividida en catorce convites de oradores... Alcalá de Henares, Joan Yñiguez de Lequerica, 1589. Fue conocida por los convites de oradores porque el tratado se organizaba en catorce combites. Hay ediciones modernas: Guzmán (1993 y 1994). 
predicadores..., pero llevará V.M. este Templo de Eloquencia ${ }^{13}$ que ha sacado a luz el Doctor Benito Carlos Quintero. (Robles 1992: 72)

Robles es continuador del afán de Jiménez Patón por crear una verdadera retórica castellana, más allá de las meras traducciones al castellano de la retórica latina que habían supuesto las tentativas de Salinas, Espinosa de Santayana y Juan de Guzmán. Pero aun siendo recurrente la presencia de la Elocuencia de Jiménez Patón en el Culto, como ha subrayado Gómez Camacho (Robles 1992: 27), el tratado de Robles responde a unos planteamientos en muchos casos opuestos a los que defiende Patón. La pretensión de este de construir una retórica castellana era un efecto derivado de su firme convencimiento de que el castellano era más antiguo que el latín, y en consecuencia debía desligarse de la lengua de Roma. Por el contrario, Robles, que combatió estos desatinos que persuadieron al propio Quevedo, concibió una retórica para un crítico en agraz y convierte la literatura clásica en el único paradigma del castellano. Cicerón y Horacio son los referentes indiscutibles de sus preceptos, y las traducciones propias que incluye de Virgilio, el Poeta por antonomasia en el Culto, de Ovidio, de Horacio y de los Salmos ilustran las reglas del arte, además del ejemplo de Garcilaso.

A diferencia del resto de las retóricas de su tiempo, incluida la de Jiménez Patón, en el Culto se deslindan nítidamente retórica y poesía. No obstante, para la exposición de los principios retóricos, especialmente los concernientes a la elocutio, Robles necesitaba un poeta que materializara en sus versos los ideales clasicistas: ese poeta era el Garcilaso comentado por Herrera. El Culto es también, y así queda expresado, una retórica para poetas, y para ellos se prescriben normas específicas. Así, pongamos por caso, los recursos de la amplificación son descritos considerando su aptitud para la prosa y la poesía ${ }^{14}$, y también se definen las virtutes narrationis diferenciando igualmente los modos de narración: histórica, oratoria y poética ${ }^{15}$.

Vamos aproximándonos a las razones que inspiran el título. La obra, concebida como un tratado para la formación de un culto en ciernes, es, en esencia, una retórica centrada en la teoría del estilo, porque la retórica constituye el viático de más sustancia en el currículo que conduce a la condición de culto; el ars dicendi, la elocuencia, son, en suma, los principales pertrechos para el culto y el crítico. Así lo declara el licenciado Sotomayor: «digo que V.M. podrá ser culto dentro de su esfera con tres cosas: procurando saber todo cuanto pudiere

13. Es la obra de Benito Carlos Quintero Templo de la eloquencia castellana en dos discursos. Aplicado el uno al discurso de los predicadores, Salamanca, Rodrigo Calvo, 1629.

14. Véanse, por ejemplo, las siguientes observaciones: «Por manera que en la prosa no se han de poner epítetos ociosos sino que obren verdaderamente algo, i en la poesía se podrán poner los que no sirven más que de adorno al arbitrio del poeta [...] Los que llaman forçosos, esto es, los que son tan fixos o proprios de la cosa o sujeto que se entiende forçosamente en oyendo el vocablo a quien pertenecen [...] Y así no podrá decir el Orador la Verde Esmeralda, porque será civilidad, el poeta sí.», Robles (1992: 118).

15. Véanse los juicios sobre el particular en Robles (1992: 93-94). 
de todas las cosas de todos géneros, i sabiendo discurrir sobre ellas según Arte, i hablar de todo como se deve hablar» (Robles 1992: 71); es decir, erudición y elocuencia.

Don Juan de Guzmán expone las estimaciones erróneas que ha oído a los falsos cultos y al vulgo, su discurso es el eco de una opinión pública contraria a la verdad que, como buen crítico, el licenciado Sotomayor se encargará de refutar. Así pues, el primero de los cinco diálogos («Trata principalmente de los nombres Crítico i Culto, i sus cualidades») se va a ocupar de desenmascarar a los falsos cultos. El planteamiento no era original. La cuestión había sido uno de los temas candentes de la controversia sobre la lengua poética desatada a partir de la recepción de los poemas mayores de Góngora. Tampoco es original Robles en los argumentos empleados, y repite muchos que podría haber extraído de discursos afines a su ideario estético. Apenas cuatro ańos antes de la redacción del Culto había publicado Juan de Jáuregui el Discurso poético (1624) para denunciar la oscuridad superflua e ilícita, origen de la corrupción generalizada que afectaba a la lengua poética. En apenas diez años después de la difusión del Polifemo y las Soledades las novedades estilísticas gongorinas se imitaban de forma arbitraria e inaceptable y habían rebasado los límites de la literatura para instalarse en el púlpito, donde los predicadores maltrataban las restricciones retóricas en sus sermones, como denuncia Robles (Robles 1992: 66-68), o incluso llegaron a establecerse en la lengua conversacional, situación que censuraron mediante la caricatura Quevedo en sus parodias idiomáticas, o el propio Robles en divertidas anécdotas incluidas en el Culto, como la que se transcribe a continuación:

De forma que sucedió -escribe- lo que me contó el Señor Obispo de Bona, Don Juan de la Sal, el año pasado, que oyendo reñir a su puerta a un negro i a un Berberisco, se asomó a la ventana, i vio que a cuantas injurias el Berberisco dezía, no le respondía el negro más que «Anda, que sá Culto». Llamándolo su Señoría i preguntándole qué quería dezir con aquellas palabras, respondió: "Que hablá, hablá, hablá i ni entendél ni entende yo», mire V.M. en qué posesión está el negocio. I así los han dividido a estos tales las personas de buen gusto, que han notado los modos de su afectación en Nítidos i Cándidos, i Ebúrneos i otros epítetos semejantes (Robles 1992: 65-66).

Para dar verosimilitud al cuentecillo lo pone en boca de alguien con la autoridad de don Juan de la $\mathrm{Sal}^{16}$, que pertenece a su mismo entorno humanístico y que gozaba de suficiente predicamento entre los aficionados a la literatura de la graciosidad: él era para entonces en Sevilla el paradigma del vir bonus et facetus ${ }^{17}$, que de algún modo constituía una de las divisas del humanismo

16. Don Juan de la Sal había nacido en la segunda mitad del siglo XVI. Fue obispo de Bona y coadjutor de la archidiócesis de Sevilla. Tuvo una participación muy activa en la vida cultural hispalense. Estaba emparentado con algunos de los ingenios de la ciudad: fue, por ejemplo, tío del poeta Juan de Jáuregui. Bonneville (1979) estudió la personalidad y la obra de este prelado.

17. Don Juan de la Sal se hizo célebre en la literatura de la sal o graciosidad por las Siete Cartas del señor don Juan de la Sal, obispo de Bona, al señor duque de Medina Sidonia, noticiándole hechos notables de cierto clérigo vecino de Sevilla, natural de Moguer, llamado el Padre Méndez (fechadas entre el 4 de julio de 1616 y el 21 de julio de ese mismo año). Estas cartas se encuentran 
sevillano más genuino ${ }^{18}$, y que justifica la presencia de los cuentos $^{19} \mathrm{y}$ facecias en el Culto. La anécdota demuestra que el vocablo culto, cuya ambivalencia en el periodo fue dilucidada con pormenor por André Collard (Collard 1967: 1314), había adoptado valores de todo punto peyorativos. Robles, como Jáuregui, recogieron un sentimiento común entre los clasicistas: lamentaban en parecidos términos el mal uso que la «ciega plebe» daba al nombre; así manifestó Jáuregui su disconformidad: «Ya veo que la ciega plebe se alarga hoy al llamar cultos los versos más broncos y menos entendidos; tanto puede con su lengua la rudeza, ¡Bien interpretan la palabra cultura!» (Jáuregui 1978: 118).

No es necesario proponer más pruebas sobre algo sabido; ya se ocupó de ello Lucien Paul Thomas (1909), que acopió numerosos testimonios donde se ironizaba con el significado que impropiamente se había atribuido a culto. Juan de Robles definió los valores propios del término. Para el beneficiado de Santa Marina los cultos eran «los que hacen sus obras con más primor que los demás»; ponderaba con esas palabras las cualidades del artífice menesteroso que lima y pule su obra hasta alcanzar la perfección deseada. Pero para llegar a tal excelencia estimaba que no era suficiente la destreza en el manejo de las reglas del arte retórica, sino que también, como citábamos antes, se alcanzaba "procurando saber todo cuanto pudiere de todas las cosas de todos géneros». Ciertamente, la tradición retórica grecolatina, Cicerón, el autor de la Rhetorica ad Herennium, Quintiliano, Demetrio habían apelado a la integración ideal de ingenio, arte y estudio. Prescribieron que la disposición natural del orador y del poeta era necesario cultivarla no solo mediante el conocimiento y el ejercicio de los preceptos, sino también por medio de la instrucción en el resto de las disciplinas del saber; como receta Robles a su joven discípulo, la variada erudición adquirida mediante el estudio constituía la principal provisión para el buen crítico y el culto. La lección estaba aprendida desde las Anotaciones herrerianas: el estudio y la erudición eran los pilares para perfeccionar el arte y estimular el ingenio.

¿Dónde reside, pues, la novedad del planteamiento de Robles? En el modelo, en el paradigma de hombre culto que propone a su alumno y que opone a la común opinión del vulgo. Él cifra, sin decirlo expresamente, las cualidades del culto en un arquetipo de otro tiempo, el del culto sevillano encarnado en la figura de su mentor y protector, el maestro Francisco de Medina, cuyas virtudes

manuscritas en dos códices facticios de la Biblioteca Capitular y Colombina de Sevilla, el 57-642 (fols. 149-169v.) y el 56-4-1 (fols. 158-175v.). También recoge estas cartas el manuscrito de la BNE 12975/26, copia decimonónica hecha por Juan de Dios Gil Lara en Sevilla el 3 de junio de 1833. Estas epístolas fueron publicadas en el t. XXXVI de la BAE, Curiosidades bibliográficas. Sobre la relación de Juan de la Sal con el duque de Medina Sidonia, destinatario de estas cartas, véase Ponce Cárdenas (2009: 112-113, n. 42).

18. Esta vertiente del humanismo sevillano ha sido estudiada por Núńez Rivera (2010). Cf. también su capítulo «El elogio burlesco en el contexto sevillano. Hacia una poética de la graciosidad", en el estudio introductorio a las Paradojas de Mosquera de Figueroa (2010: 51-60).

19. La tradición cuentística en la Sevilla del Siglo de Oro y la colección de cuentos que recoge el Culto ha sido estudiada por Gómez Camacho (2006). 
fueron compartidas por gran parte de sus coterráneos, a muchos de los cuales cita explícitamente, como Diego Girón ${ }^{20}$, o el canónigo Pacheco ${ }^{21}$. Así su discurso queda legitimado por su propia experiencia, pues evoca un mundo cultural al que nostálgicamente él siente que pertenece. Robles y su amigo Rodrigo Caro eran a esas alturas de 1631 en Sevilla la memoria de aquel humanismo, del que él mismo había sido «buen testigo», como le recuerda a su discípulo. Robles vive melancólicamente instalado en un pasado que sabe irreversible; por ello su discurso suena al canto del cisne de una época dorada que definitivamente había languidecido. Robles, que había disfrutado de una cómoda situación bajo el amparo de los arzobispos de Sevilla don Rodrigo de Castro y don Fernando Niño de Guevara, de quien fue secretario, escribió su tratado desde un retiro forzado por sus desavenencias con el arzobispo don Pedro de Castro a cuenta de las disputas de los beneficios curados de la archidiócesis ${ }^{22}$ (Robles 1992: 47 50); pero ese retiro que le comunica reiteradamente a su discípulo en el diálogo adquiere dimensión simbólica, la de vivir encastillado en el pasado, ajeno a un presente que ha violentado y pervertido aquellos valores culturales; un retiro, en fin, que lo aísla preservativamente de los nuevos tiempos. En esa perspectiva hay que interpretar la descripción de la edad de hierro ovidiana cuyos versos traduce el propio Robles para ilustrar de forma metafórica el estado de la cultura del presente. De forma implícita opone esa edad de hierro simbólica a la edad de oro que había vivido la ciudad tres décadas antes y que, en cierto modo, vindica Robles con su recuerdo.

Los humanistas sevillanos de la generación de Medina se reconocían protagonistas de participar orgullosamente en una época de esplendor de las letras. En ellos acabó germinando la conciencia de vivir un nuevo siglo de oro como sugería Francisco Pacheco por boca del dios Apolo en la profecía que dicta sobre Garcilaso en la oda latina (vv. 55-60) en honor del poeta toledano, que se incluía en los preliminares de las Anotaciones (1580) de Fernando de Herrera a las Obras de Garcilaso de la Vega; tal vez la primera formulación de la noción aureum saeculum aplicada a nuestras letras, como ejemplarmente ha estudiado José Solís de los Santos (2014).

En esa generación, a su juicio, se había acrisolado el ideal de cultura humanística. Un ideal definido por la erudición, por las privaciones del estudio y un alto grado de autoexigencia, cualidad que declara con la paráfrasis y

20. De la producción poética de Diego Girón (h. 1540-1591) se conocen unas pocas piezas y fragmentos. Girón sucedió a Juan de Mal Lara en la dirección y la docencia en la academia de «Letras humanas» que aquel había fundado en la ciudad hispalense. Especialmente recordado es su poema en hexámetros incluido en los preliminares de las Anotaciones herrerianas a las Obras de Garcilaso (Garcilaso de la Vega, 1580: 32-36). De las relaciones de Diego Girón con Fernando de Herrera y Juan de la Cueva se ha ocupado Escobar Borrego (2009).

21. Sobre el licenciado Francisco Pacheco contamos ahora con una excelente bio-bibliografía a cargo de Pozuelo (2012).

22. Estas circunstancias de la biografía de Robles son suficientemente explicadas por Alejandro Gómez Camacho en el estudio preliminar del Culto sevillano; Robles (1992: 14). 
comentario de los tópicos menores de Horacio (la adecuación del ingenio a la materia y la lima y reposo de las obras), y que ilustra con el ejemplo proverbial de Virgilio y con el de su maestro Francisco de Medina:

En su juventud escribió la canción y el prólogo a las Anotaciones a Garcilaso de Fernando de Herrera, en que ai tantos diamantes como dicciones, i otras cosillas menudas de poesía, que quemó cuando entró a ser Secretario, por parecerle que el oficio le obligaba a renunciar a las cosas apacibles i darse todo a las graves. Poco antes de su muerte se deshizo de parte de la papelería, i me dio toda la que tocava a instrumentos, pero no me dio ninguno suyo (Robles 1992: 62).

Con ello parangonaba a Medina, en su afán de excelencia, con Virgilio, argumento que había sido recreado por Jáuregui, entre otros, en la Silva al amigo malcontento de sus obras ${ }^{23}$. Tal anhelo de perfección era la causa, a su juicio, de la resistencia a publicar y divulgar la creación fuera del ambiente íntimo, académico, de los propios humanistas. Esa renuencia se convirtió en algo consabido entre los sevillanos, y así lo atestigua también el propio Robles en el Culto, asegurando que en los poetas hispalenses es en quienes "ha sido más natural esta cortedad, o temor, o recato, o como le llamáremos» (Robles 1992: 60), estimación que ilustra con los ejemplos del Licenciado Pacheco y de Fernando de Herrera, cuya poesía también se hubiera perdido de no haber sido por «la diligencia de nuestro Apeles Sevillano Francisco Pacheco que hizo este notable servicio a su patria de darlas a la estampa con notorio beneficio común» (Robles 1992: 60) ${ }^{24}$.

Aunque le resultara útil como argumento tratar la poesía de cosilla menuda para elogiar la gravedad de los negocios en los que anduvo el maestro Medina, no cabe duda de que para Robles la noción de cultura se materializaba en la poesía, y el ideal del culto se personificaba en el poeta. No juzgaba lo mismo de las obras de entretenimiento:

algunos mozos que, como con la corta vista de la poca experiencia no han llegado aún a ver el sol, tienen por luz el más dudoso crepúsculo del alba; esto es, que en habiendo leído a Guzmán de Alfarache o a Don Quijote, o estado por ventura en la segunda clase de la compañía, se sueñan catedráticos de Salamanca (Robles 1992: 65).

Ante la pregunta de don Juan: «iLuego bien se pueden llamar cultos todos los que estudiaren?» La respuesta de Robles es bien elocuente. Los ejemplos que propone son palmarios:

En rigor sí, Señor, mas paréceme que el uso lo ha adjudicado a los que hacen sus obras con más primor que los demás. I así Ovidio entre los Poetas de su tiempo llamó en particular Culto a Tibulo, su amigo [...] I nuestro divino Español Garcilasso... le dio en particular el nombre de culto a Bernardo Tasso, porque debió de hallar en su obra más calidades de cultura que en las de los otros» (Robles 1992: 63).

23. Jáuregui (1993: 263-265); para la interpretación de esta silva véanse las anotaciones a sus versos de Juan Matas (ibid.) y el estudio de Chiappini (1991).

24. Para el mejor conocimiento de las vicisitudes editoriales del volumen de la poesía de Herrera publicado por Pacheco en 1619, véase Montero y Cacho Casal (2014). 
Con el sintagma «los otros» se refiere a Tansillo y Minturno, también nombrados en el soneto a la Marquesa de Padula, doña María de Cardona (soneto XXIV): «a Tansillo, a Minturno, al culto Taso / sujeto noble de inmortal corona» (vv. 3-4). A ello respondía el joven discípulo preguntando qué calidades son esas que hallaba el poeta toledano en Tasso; y la respuesta la encuentra Robles en el verso 6 de la epístola de Garcilaso a Boscán: "estilo / presto, distinto, de ornamento puro"; de tal manera que Robles, en un elemental silogismo, identificaba las cualidades de la cultura con el estilo, más específicamente con la claridad y la pureza estilísticas; esto es, con las cualidades equidistantes del estilo de época representado por el conceptismo y el cultismo. Añade, además, para subrayar su argumento el soneto del Maestro Diego Girón que figuraba al frente de la edición de Algunas obras de Fernando de Herrera publicadas en Sevilla por Andrea Pescioni en 1582: «Fértil España a do el Pierio Vando»; soneto en el que apela Girón a los cultores del patrio estilo concentrados en el solar hispalense.

El texto de Garcilaso editado y comentado por Herrera es, en efecto, el árbitro de la cultura y de la elocuencia. Las virtudes de la elocución son ilustradas con sus versos en el Culto casi de forma exclusiva. Esto que podría representar a la altura de 1630 un cierto anacronismo, es, por el contrario, plenamente coherente con su ideario estético y con su obstinado vivir en el pasado. La lengua poética de Garcilaso representó el modelo de elocuencia que Herrera se encargó de describir por menudo para ejemplo de la nación. Por ello Robles insertó con profusión en su tratado preceptos y estimaciones de Fernando de Herrera, planteamiento que acerca El culto a las obras de crítica y preceptiva literarias de la época. Para la generación de humanistas sevillanos a la que Robles está ligado y siente aún que pertenece, Garcilaso es el principio y la meta del clasicismo, como nos hemos ocupado de exponer en otros trabajos (Rico García 2008 y 2012).

Robles permaneció nostálgicamente instalado en el recuerdo del ideal humanístico y estético que alentó las Anotaciones, y se mantuvo fiel al ideario de una generación cuyos componentes encarnaban el arquetipo del culto, el culto sevillano que él quiere describir para que sea asimilado por su joven discípulo. Si el modelo de su retórica, Baltasar de Céspedes, se sirvió de Virgilio, Robles lo hará de Garcilaso de modo exclusivo y casi excluyente, cuyos versos, en su opinión, había elevado Herrera al estatus de configuraciones retóricas. Robles no recurrió para ilustrar los preceptos a los ingenios contemporáneos más o menos implicados en las polémicas sobre la lengua poética del primer cuarto del Seiscientos, como había hecho Jiménez Patón en La elocuencia española en arte, primero, y en el Mercurio Trimegisto, después; volvió a Garcilaso con la intención programática de combatir con las armas del clasicismo los desafueros de la nueva poesía.

Tampoco creemos que Robles estuviera, ni mucho menos, a la última en poesía (ni siquiera a la penúltima). Al margen de Garcilaso, en el Culto sevillano se incluyen referencias o alusiones a composiciones que están en la órbita estética, temporal y geográfica de Robles. Tan en su órbita, que algunos de ellos 
son referidos con el plural sociativo: nuestro Rioja, nuestro Arguijo. Destaco a continuación los ejemplos más significativos. Pondera el uso que Rioja hace del participio de presente en obras poéticas: riente Aurora ${ }^{25}$, oliente rosa ${ }^{26}$ y Euro furiente $e^{27}$. También evoca el soneto 49 de «nuestro sevillano Francisco de Rioja» («iCómo a ser inmortal, Manlio, caminas!») ${ }^{28}$ porque recreaba el emblema 164 de Alciato (Inanis impetus), en el que se vitupera a los censores o críticos impertinentes.

Cuando termina su exposición de las figuras de la elocución según el orden dispuesto en la retórica de Céspedes, remite a su discípulo a la retórica de Patón por si «quiere ver algunas cosas más dellas i exemplos de poetas modernos i algunas otras que se tienen por figuras sin las dichas» (Robles 1992: 176). En la Elocuencia de Jiménez Patón se incluye como figura de repetición el eco, para referirse a los sonetos en eco. El beneficiado de Santa Marina considera su inventor a fray Luis de León en el soneto que compuso a las exequias de la reina doña Ana: «Mucho a la Magestad sagrada agrada», que había recogido el propio Patón en su retórica ${ }^{29}$; aunque, como es sabido, la autoría de fray Luis es hoy más que discutible. Este difundidísimo soneto ${ }^{30}$ es celebrado también por Rengifo como obra de un «insigne poeta» en su Arte poética española, pero sin indicación de su autoría (Díaz Rengifo 1606: 58). Antonio Carreira (2002), guiado por la atribución que consta en el manuscrito 3909 de la BNE, sugiere que acaso corresponda a Jerónimo de Asorís. Dice Robles haber visto otros sonetos en eco, que le resultan, al parecer, el colmo de la artificiosidad, pero confiesa que solo recuerda el de Lupercio Leonardo de Argensola ${ }^{31}$ que comienza "Después que al mundo el rei divino vino», dedicado a san Francisco y que solo se conserva en dos manuscritos conocidos, ambos de origen sevillano, el 17.719 de la BNE y el B 2495 (fol. 191v) de la HSA, donde se atribuye al canario Cairasco de Figueroa (Labrador, DiFranco y Rico 2006: 304), cuyos versos esdrújulos tanto predicamento tuvieron en la ciudad hispalense.

También recoge dos sonetos de consonantes duplicados, como los llama Robles, parientes de los sonetos en eco, que concurrieron en una incierta academia, que «se juntava entonces en casa de cierto personaje» (Robles 1992: 177), que no nombra y que nos atrevemos a conjeturar que se trata de la llamada por Porras de la Cámara academia de San Vicente, cuyo origen, participantes e historia es

25. Rioja (1984: 221; silva X, A la rosa, v. 12).

26. No hemos hallado este sintagma en la obra conocida de Rioja.

27. Rioja (1984: 158; soneto XVIII, v. 8).

28. Rioja (1984: 214; soneto XLIX).

29. «Soneto que hizo a las exequias de la Reina doña Ysabel el doctísimo Fray Luys de León», en Jiménez Patón (1993: 101).

30. Véase para constatarlo la nota a esta composición recogida en el Cancionero sevillano $B$ 2495 de la Hispanic Society of America (Labrador Herraiz, DiFranco y Rico 2006: 523-525). Allí se recogen 50 testimonios manuscritos e impresos.

31. José Manuel Blecua se resistió a atribuir la composición a Lupercio Leonardo de Argensola, aunque sí lo editó, tomado del manuscrito BNE 17.719, donde se atribuye a Lupercio Leonardo; véase Leonardo de Argensola (1974: xxxix). 
objeto de una investigación en marcha ${ }^{32}$. Ambos ejemplos que lee al joven don Juan son obra, declara, «del buen viejo Pamones (cuyo ingenio, si su condición hubiera dado lugar, pudiera contarse con los mayores». La inclusión de los ejemplos de Pamones denota el aprecio que la poesía de la sal tuvo entre los humanistas y poetas sevillanos desde el canónigo Pacheco o Cetina a Baltasar del Alcázar, pasando por don Juan de la Sal. Pamones fue poeta de «la bohemia del Siglo de Oro", en acertada expresión de Méndez Bejarano (1989: II, 193194). De él conocemos, por ejemplo, algunos sonetos del manuscrito 3980 de la BNE, que recoge también numerosos poemas de Alonso Álvarez de Soria, el ruiseñor del hampa, y de Juan de Ochoa, poetas todos que, en opinión de Rodríguez Marín, formaron parte de la por él denominada Academia de Ochoa $^{33}$. También está presente en el opúsculo satírico de Juan Sáez de Zumeta titulado Escolios contra Juan Baptista Pérez ${ }^{34}$. El corpus más significativo de sus poemas se encontraba en el perdido códice de la Biblioteca del Palacio Arzobispal de Sevilla, el llamado códice de Barahona o de Pamones, que afortunadamente quedó reproducido en la copia del manuscrito del Consejo RM- $5177^{35}$.

Tratando de la prosopopeya y del apóstrofe, transcribe el soneto «en que nuestro insigne sevillano don Juan de Arguijo habla con nuestro celebrado Guadalquivir así: «Tú, a quien ofrece el apartado Polo...» (Robles 1992: 116), soneto del que cabe pensar que Robles hubiera conservado una copia que se hallara entre los papeles que le dejó el maestro Medina, y, muy probablemente, conservara también original o copia de los Apuntamientos ${ }^{36}$, esto es, las enmiendas y anotaciones que hizo Medina a los sonetos de Arguijo; pues muchas de las observaciones del Maestro parece que dictan algunos preceptos del Culto. Así, se podría considerar extraída de los apuntamientos la permanente preocupación de Robles por la musicalidad de la lengua y, en especial, en los versos. Preocupación esencial en las Anotaciones y desde entonces en otros documentos críticos de linaje hispalense como el Discurso poético de Jáuregui. Más concomitancias

32. Junto con el profesor José Solís de los Santos preparamos la edición de los Escolios contra Juan Baptista Pérez de Juan Sáez de Zumeta, donde se alude a los miembros de esta academia.

33. Llama así al grupo de escritores liderados por el citado poeta y dramaturgo sevillano Juan de Ochoa, celebrado por Cervantes en el Viaje del Parnaso; véase Rodríguez Marín (1901: 162-163).

34. Los dos testimonios que nos han quedado de la vena satírico-burlesca de Zumeta son el soneto «De qué sirve la gala y gentileza» y los Escolios. El soneto fue publicado por Juan Antonio Pellicer en la Parte Primera, tomo I, de la edición del Quijote realizada por Gabriel Sancha en 1797. Los Escolios permanecen aún inéditos en tres manuscritos: el BNE 20355 (f. 265), el BPRM, II/2243(2) (f. 71) y el BUS [Biblioteca de Humanidades]) RA-158 (f. 146v).

35. Este manuscrito recoge en el fol. 198, con algunas variantes, una de las dos composiciones de Pamones incluidas en el Culto, el soneto "Ola, Bartolo, gran majadero, ola» (Robles 1992: 177).

36. Los Apuntamientos y notas de Francisco de Medina a las composiciones de Juan de Arguijo figuran en el manuscrito E-41-6929 del legado Rodríguez-Mońino de la Real Academia Española. Han sido ejemplarmente editados por Gaspar Garrote Bernal y Vicente Cristóbal como apéndice a su edición de la Poesía de Arguijo (2004: 227-248). 
aún tienen las observaciones de Medina sobre el empleo de los epítetos en la poesía de Arguijo y los juicios sobre el particular de Robles, que a veces parecen copiados a la letra. Es, además, en el tratamiento de los epítetos donde Robles prescribe más rotundamente principios exclusivos y diferenciados para la poesía. Con todo, donde permanece de modo más transparente el espíritu y la letra de los Apuntamientos en el Culto es en lo concerniente a la pureza de la lengua. A la altura de 1630, ciertamente, la resistencia de Juan de Robles ante la generalización sin restricciones de todo tipo de novedades en la lengua sonaba anacrónica, porque otros habían aceptado el nuevo estilo de época como un fatalismo contra el que no se podía ya combatir. Frente a ellos, Robles se veía a sí mismo transformado en un nuevo don Quijote, como declara, empeñado en defender «la hermosura de la Princesa Dulcinea de nuestra lengua» de las pretensiones «de algunos caballeros desmesurados» (Robles 1992: 221). No puede ser más gráfica la posición de Robles. Postura que se resume en las siguientes palabras: «La oración ha de ir compuesta forçosamente por la mayor parte de Vocablos puros, simples, nativos, propios i conocidos i usados, de modo que sea verdaderamente el lenguaje español» (Robles 1992: 130).

Esta defensa a ultranza de la pureza de la lengua se hace frente a los desmanes alcanzados en el primer cuarto del siglo, pero también frente a los que consideraron el castellano más antiguo que el latín ${ }^{37}$. Desvinculando el español de su modelo, la pureza dejaba de tener pertinencia como cualidad, porque perdía su referente, y la latinitas clásica dejaba de ser un valor aplicable a la lengua y retórica romances. Todo ello concurre en la doctrina sobre la invención de vocablos. Robles sigue a Herrera para llegar, cincuenta años después, a sostener la tesis contraria. Si en Herrera la invención de vocablos no tiene tasa si está al servicio del adorno; en Robles, como había sido en Jáuregui, pues ambos seguían a Horacio en este punto, había de ajustarse a rigurosas restricciones. Era la consecuencia, en definitiva, de los despropósitos a los que los falsos cultos habían llevado la lengua literaria. Gómez Camacho, editor del Culto, subrayaba la distancia que en este punto separaban las ideas de Robles y de su maestro Medina en el prólogo a las Anotaciones, pues, en efecto, para Robles el español en su tiempo era una lengua madura para la que cualquier novedad suponía un perjuicio, mientras que Medina en 1580 reclamaba autores que recrearan una «lengua adornada de nueva i admirable pompa». No reparaba, sin embargo, Gómez Camacho, que un cuarto de siglo después de 1580, en 1605, fecha aproximada de la redacción de los Apuntamientos, Medina se había vuelto mucho menos permisivo con las novedades y sus observaciones intentaban conciliar adorno y novedad con pureza, en términos muy similares a como lo harían después Robles en el Culto o Jáuregui en el Discurso poético.

El telón de fondo del Culto no era otro que la controversia sobre la lengua literaria que había tenido su origen en la difusión de los poemas mayores de Góngora. Sin embargo, Robles eludió tratar de forma explícita esta cuestión, ni

37. Para la cuestión remitimos al modélico análisis que hace Alejandro Gómez Camacho en el estudio introductorio a su edición del Culto; Robles (1992: 21-25). 
siquiera cuando discurre sobre las causas de la oscuridad. Solo hay en el Culto alusiones y referencias veladas. En 1631 la estimación de la obra de Góngora era casi unánime. Como unánime era la censura de las inaceptables imitaciones que muchos realizaban de sus hallazgos estilísticos en la poesía, en los corrales de comedias o en el púlpito. Estos eran los mal llamados cultos.

El Culto sevillano fue, en fin, un tratado de retórica difícil de clasificar por algunas de las razones expuestas. Atípico, disconforme con el estado de la cultura y de la elocuencia en su tiempo. La cronología de su vida brindó a Robles la ocasión de asistir al periodo de más fecundas innovaciones de la literatura del Siglo de Oro y de participar en el juicio de los cambios que transformaron la lengua literaria. Su impermeabilidad ante las novedades estéticas convierte a Robles en el paradigma del conflicto, vivido con vehemencia durante el siglo XVII, entre la pervivencia y la quiebra de los ideales renacentistas, fundados en principios estéticos intemporales. La vocación crítica del Culto sevillano, tan encarecida por Vilanova, se percibe en la denuncia y la caricatura de los pseudocultos, de los eruditos a la violeta de su tiempo. Frente a estos, Robles evocó unos ideales irrealizables que ya pertenecían al pasado; e invocó para conjurar la decadencia del presente a los hombres que encarnaron el modelo de culto sevillano: Diego Girón, el licenciado Pacheco, Pedro Vélez de Guevara, Medina, Herrera. Pero la melancolía que destilan las palabras del licenciado Sotomayor en sus consejos al joven don Juan son recuerdo de una dicha perdida hacía mucho tiempo, de la que Robles había sido testigo.

La resistencia de Robles a los nuevos tiempos fue de una terquedad que ni siquiera compartió su más íntimo amigo, Rodrigo Caro, quien, como Robles, permaneció aislado en una Sevilla, para entonces, 1630, decadente, de la que se había marchado, en el séquito de Olivares con la privanza, lo más granado de su generación: Rioja, Calatayud, Jáuregui, Soria Galvarro, Venegas Saavedra, el conde de Roca... Una ciudad significada en esos ańos por la defensa del patronato único de Santiago ${ }^{38}$, por la santificación del rey Fernando III y otros negocios de este tenor. En el romance que dedica a Robles Rodrigo Caro, entre bromas y veras, le confesaba, por boca de un demonio o geniecillo, su claudicación ante los nuevos tiempos y el nuevo gai saber en el siguiente verso: "Aquesta que miráis torre (que también yo gongorizo)»" ${ }^{39}$. El bueno de Robles, quizá por no ser menos, hizo su concesión al gongorismo en el Culto citando el más conocido verso del poeta cordobés, pero un lapsus imperdonable delató su desafecto: «Estos, que me dictó, versos, Talía» (Robles 1992: 242). Ni aun queriendo, el más perverso enemigo de Góngora habría citado peor el primer verso del Polifemo.

38. Sobre la intervención de Robles en la contienda sobre el copatronato de Santiago y santa Teresa, véase Gómez Camacho y Rico García (2014).

39. Se trata del verso 87 del Romance al Licenciado Juan de Robles en la posesión del beneficio de la Membrilla, relato del viaje que hace Caro en julio de 1627 para tomar posesión del mencionado beneficio en nombre de Juan de Robles. Véase Caro (2000); el citado romance en las pp. 162-168. 


\section{Bibliografía}

Arguijo Juan de, 2004, Poesía, ed. de Gaspar Garrote Bernal y Vicente Cristóbal, Sevilla, Fundación José Manuel Lara (col. Clásicos Andaluces).

Artaza Elena, 1997, Antología de textos retóricos españoles del siglo XVI, Bilbao, Universidad de Deusto.

Bonneville Henry, 1979, «Dos testimonios inéditos de don Juan de la Sal, obispo de Bona, sobre la vida en Sevilla (1623-1626)", en Hommage des hispanistes français à Nöel Salomon, Barcelona, Laia, pp. 109-122.

Caro Rodrigo, 2000, Poesía castellana y latina e inscripciones originales, ed. Joaquín Pascual Barea, Sevilla, Diputación.

Carreira Antonio, 2002, "Un cancionero del siglo XVI con atribuciones a Barahona de Soto y su círculo granadino», en José Lara Garrido (ed.), De saber poético y verso peregrino. La invención manierista de Luis Barahona de Soto, Málaga, Anejo de Analecta Malacitana, pp. 27-45.

Casas Elena, 1980, La Retórica en España, Madrid, Editora Nacional.

Chiappini Gaetano, 1991, «El fantasma de la perfecta forma en las silvas de Jáuregui», en Begońa López Bueno (ed.), La silva, Sevilla, Universidad, pp. 181-211.

Collard André, 1967, Nueva poesía. Conceptismo, culteranismo en la crítica española, Madrid, Castalia.

Díaz Rengifo Juan, 1606, Arte poética española, Madrid, Juan de la Cuesta.

Méndez Bejarano Mario, 1989, Diccionario de Escritores, Maestros y Oradores de Sevilla y su actual provincia, Tipografía Gironés, Sevilla, 1922-1925, 3 vols. (ed. facsímil en un vol. por Padilla libros, Sevilla).

Escobar Borrego Francisco Javier, 2009, «La obra poética de Juan de la Cueva en el entorno sevillano (con un excurso sobre sus vínculos con Diego Girón y Fernando de Herrera)", Rivista de Filologia e Letterature ispaniche, 12, pp. 35-70.

Garcilaso de la Vega, 1580, Obras de Garcilaso de la Vega con anotaciones de Fernando de Herrera, Sevilla, Alonso de la Barrera.

Gómez Camacho Alejandro, 2006, «Los cuentos en la obra de Juan de Robles», Etiópicas, 2, pp. 202-254.

Gómez Camacho Alejandro y José Manuel Rico García, 2014, «La participación de Juan de Robles en la controversia sobre el patronato de santa Teresa», La Perinola, 18, pp. 255-287.

Guzmán Juan de, 1993, Primera parte de la Rhetorica, introducción, texto crítico y notas de Blanca Periñán, Pisa, Giardini Editori e Stampatori, 2 vols.

Guzmán Juan de, 1994, Primera parte de la Rhetórica, Madrid, El Crotalón.

Jauralde Pablo (dir.), 2010, Diccionario filológico de literatura española. Siglo XVII, Madrid, Castalia, 2 vols.

Jáuregui Juan de, 1978, Discurso poético, ed. de Melchora Romanos, Madrid, Editora Nacional.

Jáuregui Juan de, 1993, Poesía, ed. de Juan Matas Caballero, Madrid, Cátedra. Jiménez Patón Bartolomé, 1993, Elocuencia española en arte, ed. de Francisco J. Martín, Barcelona, Puvill Libros. 
Labrador Herraiz, José J., Ralph DiFranco y José Manuel Rico (eds.), 2006, Cancionero sevillano B 2495 de la Hispanic Society of America, , Sevilla, Universidad.

Leonardo de Argensola, Lupercio, 1974, Rimas, ed. José Manuel Blecua, Madrid, Espasa-Calpe.

López Bueno Begońa, 2010, «Retóricas y canon poético en el siglo XVII: los ecos de un disenso", en Begońa López Bueno (dir.), El canon poético en el siglo XVII, Sevilla, Universidad, pp. 49-71.

Martí Antonio, 1972, La preceptiva retórica española en el Siglo de Oro, Madrid, Gredos.

Montero Juan y Marta Cacho Casal, 2014, «Francisco Pacheco editor de obras de Fernando de Herrera: análisis de un documento inédito", Bulletin of Spanish Studies, XCI, pp. 1-14.

Mosquera de Figueroa Cristóbal, 2010, Paradojas, ed. de Valentín Núñez Rivera, Salamanca, Universidad.

Núñez Rivera Valentín, 2010, «Otra poesía sevillana del Siglo de Oro. Entre sales y graciosidad», en Andrés Sánchez Robayna (ed.), Literatura y territorio. Hacia una geografía de la creación literaria en los Siglos de Oro, Las Palmas de Gran Canaria, Academia Canaria de la Historia, pp. 513-537.

Ponce Cárdenas Jesús, 2009, «Góngora y el conde de Niebla. Las sutiles gestiones del mecenazgo", Criticón, 106, pp. 99-146.

Pozuelo Calero, Bartolomé, "Pacheco, El Licenciado Francisco», en Diccionario biográfico y bibliográfico del Humanismo español (siglos XV-XVII), ed. J. F. Domínguez, Madrid, Ediciones Clásicas, 2012, pp. 629-634.

Rico García José Manuel, 2008, "Conciencia literaria y canon en el siglo XVI. El Humanismo en busca de su auctor», en Begoña López Bueno (dir.), El canon poético en el siglo XVI, Sevilla, Universidad, pp. 109-140.

Rico García José Manuel, 2012, «Agrias querellas en la Nueva Roma: de Pacheco a Pacheco", en Begońa López Bueno (dir.), en La "Idea de poesía sevillana en el Siglo de Oro", Sevilla, Universidad, pp. 319-352.

Rioja Francisco de, 1984, Poesía, ed. Begoña López Bueno, Madrid, Cátedra.

Robles Juan de, 2010, Tardes del Alcázar. Doctrina para el perfecto vasallo, ed. de Antonio Castro Díaz, Sevilla, Ayuntamiento.

Robles Juan de, 1992, El culto sevillano, ed. de Alejandro Gómez Camacho, Sevilla, Universidad.

Rodríguez Marín Francisco, 1901, El Loaysa de "El celoso extremeño». Estudio históricoliterario, Tip. de Francisco de P. Díaz, Sevilla.

Salinas Miguel de, 1999, Rhetórica en lengua castellana, ed. de Encarnación Sánchez García, Napoli, L'Orientale Editrice.

Solís de los Santos José, 2014, «Siglo de Oro para las Anotaciones de Herrera», en Luis Gómez Canseco, Juan Montero y Pedro Ruiz Pérez (eds.), Aurea poesis. Estudios para Begoña López Bueno, Córdoba, Universidades de Córdoba, Huelva y Sevilla, pp. 99-109.

Thomas Lucien-Paul, 1909, Essai sur le lyrisme et preciosité cultiste en Espagen, étude historique et analitique, Paris, Honoré Champion.

Vilanova Antonio, 1951, «Preceptistas españoles de los siglos XVI y XVII», en Historia general de las literaturas hispánicas, Barcelona, Barna, IV, pp. 567-692. 
